\title{
REVIEW
}

\section{Regulation of distinct pools of amyloid $\beta$-protein by multiple cellular proteases}

\author{
Malcolm A Leissring ${ }^{1 *}$ and Anthony J Turner ${ }^{2}$
}

\begin{abstract}
Alzheimer's disease (AD) is a progressive, age-related neurodegenerative disorder characterized by extracellular and intracellular deposition of the amyloid $\beta$-protein $(A \beta)$. The study of rare, familial forms of AD has shown that sustained elevations in the production of $A \beta$ (either all forms or specific pathogenic variants thereof) are sufficient to trigger the full spectrum of cognitive and histopathological features of the disease. Although the exact cause or causes remain unknown, emerging evidence suggests that impairments in the clearance of $A \beta$, after it is produced, may underlie the vast majority of sporadic $A D$ cases. This review focuses on $A \beta$-degrading proteases (ABDPs), which have emerged as particularly important mediators of $A \beta$ clearance. A wide variety of proteases that - by virtue of their particular regional and subcellular localization profiles - define distinct pools of $A \beta$ have been identified. Different pools of $A \beta$, in turn, may contribute differentially to the pathogenesis of the disease. The study of individual ABDPs, therefore, promises to offer new insights into the mechanistic basis of AD pathogenesis and, ultimately, may facilitate the development of effective methods for its prevention or treatment or both.
\end{abstract}

\section{Review}

\section{Introduction}

A defining feature of Alzheimer's disease (AD) is the pathological accumulation of proteinaceous deposits, known as amyloid 'plaques', in brain regions important for learning, memory, and cognition [1]. The primary constituent of amyloid plaques is the amyloid $\beta$-protein $(A \beta)$, a complex mixture of peptides ranging from 37 to 43 amino acids in length [1]. $A \beta$ is a fragment of the amyloid precursor protein (APP) derived by the successive action of two proteolytic activities known as $\beta$ - and $\gamma$-secretase [2]. $\beta$-secretase, which effects the first step in $A \beta$ production, cleaves primarily at a single site, thereby determining the $\mathrm{N}$-terminus of $\mathrm{A} \beta$ [3]. $\gamma$-secretase, by contrast, can cleave at many possible positions, resulting in $A \beta$ peptides of varying length because of heterogeneity at their C-termini [2].

Because excessive $A \beta$ deposition is a strict requirement for a definitive diagnosis of $A D, A \beta$ has quite naturally been proposed to play a causal role in the disease. In formal terms, the 'amyloid cascade hypothesis' postulates that $A \beta$ accumulation is sufficient to

\footnotetext{
* Correspondence: leissring@mayo.edu

'Department of Neuroscience, Mayo Clinic, Birdsall Building, Room 117, Jacksonville, FL 32224, USA

Full list of author information is available at the end of the article
}

trigger the full spectrum of neuropathological and cognitive sequelae characterizing $\mathrm{AD}$ [4]. The main contours of this hypothesis have been validated by a large body of evidence. However, over time, the amyloid cascade hypothesis has undergone several salient refinements. For example, initially, amyloid plaques per se were considered to be the primary culprits in the pathogenesis of $\mathrm{AD}$. As experimental data accumulated, however, the focus began to shift to other forms of aggregated $A \beta$, including $A \beta$ fibrils, $A \beta$ protofibrils, and, finally, $A \beta$ oligomers [5]. Likewise, findings from human molecular genetics showed that the relative abundance of longer forms of $A \beta$ (that is, $A \beta 42$ ), rather than merely the total amount of $A \beta$, was another critical determinant of $\mathrm{AD}$ pathogenesis $[6,7]$.

In this review, we focus on a further, relatively unexplored refinement of the amyloid cascade hypothesis namely, the idea that certain pools of $A \beta$ are more relevant than others to the pathogenesis of $\mathrm{AD}$. As we discuss, different pools of $A \beta$ are determined to a large extent by different $\mathrm{A} \beta$-degrading proteases (A $\beta \mathrm{DPs}$ ) [8]. Hence, the study of A $\beta D P$ s offers a unique window into a poorly understood aspect of $\mathrm{AD}$ pathogenesis. 


\section{Pools of amyloid $\beta$-protein are determined by multiple factors}

Broadly speaking, a 'pool' of $\mathrm{A} \beta$ can be defined as a spatially distinct subset of the total population of $A \beta$ molecules [8]. In conceptualizing the factors contributing to a given pool of $A \beta$, it is instructive to consider the 'life history' of individual A $\beta$ molecules. Each will be characterized by a unique time and location of initial production (that is, 'birth') and of ultimate destruction or deposition (that is, 'death'). The time between these two events (that is, 'life span') is another key factor, as it is a principal determinant of the extent to which a given $A \beta$ molecule can translocate [8].

Extending this analogy, a pool of $A \beta$ can be likened to the population of a country. Some individuals will be born in the country, some will immigrate from elsewhere. Some individuals will die in the country, others will emigrate and die elsewhere. The country's total population is thus determined by multiple factors: the relative rates of birth and death, the average life span of individuals who are born and die in the country, the immigration and emigration rates, and the duration of stay of migrants. By analogy, a given pool of $A \beta$ is defined by the rates of production and catabolism (or deposition) of $A \beta$, by the average life span of resident $A \beta$ molecules, and by the rates of trafficking of $A \beta$ into and out of the pool. Each of these factors is considered, in turn, below.

\section{Amyloid $\beta$-protein production}

The production of $A \beta$ is arguably the most stable factor contributing to different pools of $A \beta$. The sites of $A \beta$ production are, by necessity, determined by the colocalization of APP and $\beta$ - and $\gamma$-secretase. As confirmed by a recent study [9], the levels of APP, $\beta$ secretase (BACE1), and $\gamma$-secretase (presenilin 1) differ only modestly between different brain regions. APP (specifically the amyloidogenic 695 isoform [10]) and BACE1, however, are expressed predominantly in neurons, making neurons the principal locus of $A \beta$ generation [11].

The vast majority of $A \beta$ is produced intracellularly, primarily within early and late endosomes [11-14]. Although there is some evidence that $A \beta$ can be produced at the cell surface [15], $\beta$ - and $\gamma$-secretase are both aspartyl proteases with acidic $\mathrm{pH}$ optima [2]; thus, the activity of these proteases in non-acidified compartments is likely to be low.

In sum, $\mathrm{A} \beta$ production takes place within a limited subset of subcellular compartments, primarily within neurons. As such, the production of $A \beta$ represents an important, albeit relatively homogeneous, determinant of different pools of $\mathrm{A} \beta$.

\section{Trafficking of amyloid $\beta$-protein}

Whereas the sites of $A \beta$ production are relatively limited, $A \beta$ deposition is known to occur in multiple, diverse loci, including the extracellular space, endosomes, lysosomes, and multivesicular bodies and even within mitochondria and cytosol $[16,17] . A \beta$ is well established to be secreted into the extracellular space constitutively, via recycling endosomes and, to a lesser extent, via production at the cell surface [14]. A portion of endosomes are normally trafficked to lysosomes, suggesting that a significant fraction of newly generated $A \beta$ is likely directed to this compartment [18].

Accruing evidence suggests that $\mathrm{A} \beta$ can also accumulate within mitochondria [19]. Although the exact pathway or pathways taken to reach mitochondria have not been delineated with certainty, it is notable that all components of the presenilin $/ \gamma$-secretase complex have been detected within mitochondria [20], and recent evidence suggests that some de novo production may occur there [21].

Accumulation of $A \beta$ in the cytosol is another widely reported yet counterintuitive finding $[17,18]$. Translocation of $A \beta$ into the cytosol has been proposed to take place via passive leakage from intracellular compartments such as lysosomes [22] or endoplasmic reticulum (ER) vesicles [23]. Although $\mathrm{A} \beta$ that reaches the cytosol is expected to be rapidly degraded by insulin-degrading enzyme (IDE) or the proteasome or both [23], this pathway might account for a small but important pool of $A \beta$ that may arise under certain pathological conditions. Supporting this view, several studies in cultured cells indicate that cytosolic $\mathrm{A} \beta$ is particularly cytotoxic [24,25].

Transcellular transport of $A \beta$ is another important topic that is only partially understood. Here, it is important to recognize that very little 'free' $A \beta$ exists outside the cell and that most is bound to various $A \beta$-binding proteins [26]. Among the more important of these are apolipoproteins E and J (ApoE and ApoJ) [26]. ApoE is the strongest known genetic risk factor for $\mathrm{AD}$ [27], and a human molecular genetic study recently identified ApoJ as an important factor as well [28], suggesting that transcellular trafficking of $A \beta$ is particularly relevant to AD pathogenesis. Although there are numerous hypotheses about the physiological function or functions of ApoE and ApoJ, there is general agreement that they are involved in the clearance of $A \beta$, likely by mediating the delivery of extracellular $A \beta$ to intracellular compartments responsible for $A \beta$ degradation (that is, lysosomes) [27].

In conclusion, although the sites of $\mathrm{A} \beta$ production are relatively fixed, the peptide can be transported to a wide range of intra- and trans-cellular destinations, both by simple diffusion and by specific trafficking pathways, usually mediated by $\mathrm{A} \beta$-binding molecules. 


\section{Amyloid $\beta$-protein degradation}

Ultimately, all $A \beta$ peptides undergo one of only two possible fates: proteolytic degradation or permanent deposition into plaques or other insoluble aggregates. Since only a tiny fraction of all $A \beta$ becomes permanently deposited, the overwhelming majority is degraded by one protease or another [29]. Proteolytic degradation, therefore, directly determines the life span of most $A \beta$ molecules and, by extension, also determines the extent to which they can be trafficked away from sites of production.

$\mathrm{A} \beta$ can be degraded by a large number of proteases, each of which exhibits distinctive regional, cellular, and subcellular localization profiles [8]. The complete list of A $\beta D P s$ has been reviewed elsewhere $[8,29,30]$, but for illustrative purposes, we provide examples of proteases with particularly divergent subcellular localizations in Table 1. In general, more than one $\mathrm{A} \beta \mathrm{DP}$ is present within each subcellular compartment [8]. This is particularly evident in the case of the extracellular space, where numerous A $\beta D P$ s are known to exist [8]. Thus, for a given subcellular compartment, the relative contribution of each protease to the overall level of $\mathrm{A} \beta$ will depend on additional factors, such as the relative abundance and specific catalytic efficiencies of each protease.

Certain A $\mathrm{BDPs}$ also have the potential to impact the relative abundance of more pathogenic forms of $A \beta$ (for example, $A \beta 42$ ) relative to more inert forms (for example, A 340 ). For example, cathepsin B (CatB) exhibits carboxypeptidase activity that enables it to convert $A \beta 42$ to A $\beta 40$ [31], as has also been reported for angiotensinconverting enzyme [32]. Similarly, cathepsin D (CatD) has been shown to degrade $A \beta 42$ and $A \beta 40$ with markedly different kinetics, resulting in elevated cerebral A $\beta 42 / 40$ ratios in CatD-null mice [33].

When the above factors are taken together, a picture emerges wherein different pools of $A \beta$ are defined by spatially distinct subcellular compartments containing multiple $A \beta D P s$ acting in concert to regulate the local concentration of $A \beta$. Diffusion and active transport between compartments also play important roles, such that local levels of $A \beta$ are defined primarily by the joint action of transport and degradation (as opposed to production).

\section{Evidence that specific pools of amyloid $\beta$-protein differentially impact the pathogenesis of Alzheimer's disease}

Despite several decades of intensive study of the molecular pathogenesis of $\mathrm{AD}$, remarkably little work has investigated which pools of $A \beta$ are most pathogenic. Several factors appear to have contributed to the relative dearth of information on this topic. The first is the technical matter of detecting distinct pools of $A \beta$, particularly within distinct intracellular compartments. It is exceptionally difficult to unambiguously detect intracellular pools of $A \beta$ with antibodies, given the problem of cross-reactivity with intracellular APP, the C-terminal fragments of APP, and catabolites of A $\beta$ [17]. Second, extracellular pools of $A \beta$ tend to be so overwhelmingly dominant, particularly when plaques are present, that it complicates the reliable detection of changes in intracellular pools of A $\beta$. Finally, most studies of AD have been performed either in post-mortem human brain tissue or in mouse models that overexpress full-length APP harboring AD-causing mutations, yet neither of these experimental paradigms involves the selective manipulation of individual pools of $A \beta$.

\section{Evidence from post-mortem tissues}

Notwithstanding the many caveats that apply, the analysis of post-mortem tissues has yielded several insights into the possible relevance of different pools of $A \beta$ to $\mathrm{AD}$ pathogenesis. Perhaps the most remarkable is the observation that there are many cognitively normal

Table 1 Examples of amyloid $\beta$-protein-degrading proteases with distinct localization profiles

\begin{tabular}{|c|c|c|c|c|c|c|c|c|}
\hline$A \beta D P$ & Cytosol & Nucleus & Mitochondria & Peroxisomes & Endosomes & Lysosomes & ER/Golgi & Extracellular \\
\hline Plasmin & & & & & & & - & + \\
\hline NEP & & & & & & & + & + \\
\hline ECE1 & & & & & + & $(+)$ & - & - \\
\hline ECE2 & & & & & + & + & & \\
\hline IDE & + & + & + & + & - & & & + \\
\hline PreP & & & + & & & & & \\
\hline CatB & & & & & + & + & + & + \\
\hline CatD & - & & & & $(+)$ & + & - & - \\
\hline
\end{tabular}

Plus sign indicates present and proteolytically active, and minus sign indicates present but not active (inactivity is due to pH or other factors); (+) indicates mixed evidence for activity. $A \beta D P$, amyloid $\beta$-protein-degrading protease; $C a t B$, cathepsin $B$; $C a t D$, cathepsin $D$; $E C E$, endothelin-converting enzyme; $E R$, endoplasmic reticulum; IDE, insulin-degrading enzyme; $N E P$, neprilysin; PreP, presequence protease. 
individuals whose brains are nonetheless replete with extracellular deposits of $A \beta$ [34]. It is difficult to fully assimilate this finding with evidence from animal models showing that extracellular, soluble forms of $A \beta$ (particularly oligomers) can contribute directly to memory deficits that, notably, can be rapidly reversed by antibodies or other A $\beta$-lowering treatments [35]. Along similar lines, immunotherapies that can be presumed to reduce the extracellular pool of free $A \beta$ have shown little or no evidence of efficacy on cognitive outcomes in clinical trials. These results do not preclude the idea that the extracellular pool of $A \beta$ plays some role in the etiology of $\mathrm{AD}$, but they do cast doubt on the popular notion that elevations in extracellular $A \beta$ are sufficient to produce mnemonic deficits in real time in humans.

Beyond these negative results, a considerable body of work has implicated intracellular pools of $A \beta$ in the pathogenesis of $\mathrm{AD}$-type pathology in post-mortem tissue [17]. For example, intracellular $A \beta$ has been shown to correlate with neurofibrillary tangle-bearing neurons $[16,36]$. Accumulation of intracellular $A \beta$ has also been shown to precede extracellular plaque formation in patients with Down syndrome [37], suggesting that it is an early event. Despite extensive evidence for intraneuronal $\mathrm{A} \beta$ accumulation in $\mathrm{AD}$ and related disorders from postmortem tissues [17], these studies suffer from several shortcomings. First, there is considerable uncertainty about whether $A \beta$ can be distinguished from APP and $\mathrm{A} \beta$ catabolites by immunohistochemical methods. Second, in general, they fail to define the precise sub cellular location of the intracellular $A \beta$.

\section{Evidence from animal models over expressing different pools of amyloid $\beta$-protein}

Some of the most compelling evidence supporting the view that particular pools of $A \beta$ can be especially pathogenic comes from comparison of the relatively few animal models that have explicitly directed $A \beta$ exclusively to one compartment. For example, LaFerla and colleagues [38] developed multiple transgenic mouse lines over expressing human $A \beta 42$ exclusively in the cytosol of neurons. The resulting mice exhibited extensive neuronal degeneration, apoptosis, reactive gliosis, and premature lethality. Neurodegeneration and apoptosis have been noticeably absent in most other animal models over expressing APP.

The striking phenotype triggered by over expression of cytosolic $A \beta$ is in contradistinction to other models that have directed $A \beta$ expression to other compartments. McGowan and colleagues [39] developed novel lines of mice capable of selectively producing either $A \beta 40$ or A $\beta 42$ principally in the extracellular space. This was achieved by expressing a fusion protein composed of the British familial dementia-associated BRI gene with the
$\mathrm{A} \beta$ sequence fused in frame at its $\mathrm{C}$-terminus [40]. The BRI-A $\beta$ fusion protein is then cleaved by furin-like proteases, resulting in the production of $A \beta$ principally within the secretory pathway [40]. These mice show ample amyloid plaque pathology and plaque-associated gliosis [39] but, like most animal models over expressing holo-APP, exhibit no evidence of neurodegeneration. Taken together, the findings emerging from animal models expressing $A \beta$ in distinct compartments strongly support the hypothesis that distinct pools of $A \beta$ differ markedly in their ability to trigger the full complement of pathological features characterizing $\mathrm{AD}$. In general, these finding suggest that intracellular pools of $A \beta$ are more pathogenic than the extracellular pool. However, additional clarity about which intracellular pools of $\mathrm{A} \beta$ are pathophysiologically meaningful to AD pathogenesis is needed.

\section{Evidence from animal models targeting spatially distinct amyloid $\beta$-protein-degrading proteases}

A complementary approach to investigating different pools of $A \beta$ is manipulating $A \beta D P$ s that are normally localized to or artificially targeted to distinct cellular compartments. For this approach, as for the approach of overexpressing different pools of $A \beta$, only a limited amount of data are currently available. In addition, the extent to which different compartments - and specific brain regions - can be selectively manipulated depends in large part on the exact localization profiles of the proteases under investigation. A further caveat stems from the fact that all proteases regulate many different substrates besides $A \beta$, so interpretation of results is not always straightforward. Nevertheless, the few studies taking this approach have already generated several significant findings, and there is strong reason to believe that additional studies of this type will yield additional insights into the role of specific pools of $A \beta$ in the pathogenesis of $\mathrm{AD}$.

\section{Cellular studies}

Studies in cultured cells cannot model all or even most features of AD pathology, but they do provide a readily manipulated, reductionistic system with which to study the impact of different A $\beta D P$ s on distinct pools of $A \beta$. For example, over expression of either of two spatially distinct A $\beta D P s$ - IDE or neprilysin (NEP) (Table 1) - in APP-overexpressing cells was found to differentially impact biochemically distinct pools of $A \beta$ [41]. Over expression of IDE resulted in a marked reduction in detergent-soluble pools of intracellular and extracellular $\mathrm{A} \beta$ as well as detergent-insoluble (formic acid-extracted) intracellular pools of $A \beta$ [41]. By contrast, expression of NEP reduced the detergent-insoluble pool of $A \beta$ markedly, but only partially reduced extracellular $A \beta$, and did not affect intracellular soluble $\mathrm{A} \beta$ [41]. These results 
show not only that different pools of $A \beta$ can indeed be selectively targeted by different A $\mathrm{DDPs}$ but also that there is some degree of correspondence between traditional biochemical $A \beta$ fractionation methods and different pools of $\mathrm{A} \beta$ - even in the absence of amyloid plaque formation.

In another cell-based study, chimeric forms of NEP were engineered to be selectively targeted to different compartments, including ER, trans-Golgi network, early/ recycling endosomes, or lipid rafts. Then, after viral infection of primary neurons, the relative impact on extracellular $A \beta$ and on guanidinium-extractable intracellular $A \beta$ was assessed [42]. Wild-type NEP was found to be the most effective at reducing both pools, suggesting that NEP is normally operative in multiple cellular compartments [42]. The ER-targeted NEP chimera was the least effective at degrading the extracellular pool of $A \beta$, but intracellular pools of $A \beta 40$ were reduced with equal efficiency by all the NEP chimeras. Interestingly, only marginal reductions were observed on intracellular A 342 [42]. In light of more recent work showing that NEP is localized primarily at the plasma membrane [43], it may be that extracellular NEP activity can influence intracellular $A \beta$ levels to a certain degree, perhaps during the process of internalization of extracellular $A \beta$.

\section{Animal models over expressing spatially distinct amyloid $\beta$ - protein-degrading proteases}

As we have seen, in cultured cells, over expressing spatially distinct proteases can result in differential effects on biochemically distinguishable pools of $A \beta$. What, then, is the impact in vivo? As with so many other approaches we have considered thus far, only a limited number of studies have been conducted to date. Transgenic mice over expressing either IDE or NEP under the control of the same promoter were developed and subsequently crossed to the J20 line of APP transgenic mice [44]. The IDE transgenic line expressed approximately $100 \%$ more IDE than wild-type mice, and the APPxIDE double-transgenic line exhibited an approximately 50\% reduction in both soluble and insoluble $A \beta 40$ and $A \beta 42$ at 8 to 10 months of age, together with reduced plaque burden and associated microgliosis and astrocytosis. The NEP line, by contrast, expressed approximately $700 \%$ more NEP than wild-type mice, and the APPxNEP cross exhibited essentially no amyloid pathology or associated pathology up to 14 months of age, together with an $80 \%$ to $95 \%$ reduction in soluble and insoluble pools of $A \beta$ at 10 months of age [44]. So, does this study suggest that the pools of $A \beta$ regulated by NEP are more important for AD-type pathology than those regulated by IDE? Unfortunately, the conclusions that can be drawn from this study are complicated by the fact that very different levels of expression of the different proteases were obtained [44].
Beyond this single study, we are aware of no studies that explicitly compare and contrast the effect of overexpressing different $\mathrm{A} \beta \mathrm{DP}$ s in animal models of $\mathrm{AD}$. We believe that such studies are warranted and, properly implemented, are likely to yield important insights into the relative impact of different pools of $A \beta$ to AD pathogenesis. However, a lesson to be learned from the aforementioned study is that there is a 'ceiling' of protease overexpression beyond which no $\mathrm{A} \beta$ deposition will occur; thus, it may be more informative to assess the relative impact of different proteases at lower levels of overexpression.

\section{Animal models with genetic deletion of spatially distinct amyloid $\beta$-protein-degrading proteases}

The study of animal models with genetic deletion of different $A \beta D P$ Ps provides important insights that cannot be derived from overexpression paradigms. Genetic deletion of a protease normally involved in $A \beta$ catabolism can provide relatively quantitative information about the degree to which a protease normally contributes to the overall economy of $A \beta$ [45]. At the same time, the study of knockout mice can also be constrained by such factors as premature lethality, compensatory changes, and/ or peripheral consequences that can indirectly impact $A \beta$ metabolism independently of direct effects on $A \beta$ catabolism [45]. Nevertheless, several important lessons have emerged from this category of investigation. The first lesson is that deletion of specific A $\beta D P$ s can result not only in quantitative effects on the overall economy of $A \beta$, as would be expected, but also in qualitative differences, both in the kinds of amyloid aggregates that are impacted and in the specific types of pathology that are observed. For example, deletion of NEP in the J9 line of APP transgenic mice resulted not only in a doubling of steady-state $A \beta$ levels, as expected, but also in the emergence of cerebral amyloid angiopathy [46], a pathological feature that was not present in the same line expressing normal levels of NEP. Deletion of NEP in a different APP transgenic line (APP23) resulted in the same doubling of overall $A \beta$ levels, but in this case oligomeric forms of $A \beta$ were found to be increased significantly [47].

Two other AßDPs present in lysosomes -CatB and CatD - have been genetically deleted in animal models of $\mathrm{AD}$ and serve as illustrative points of comparison with the latter studies. For example, deletion of CatB in APP transgenic mice resulted in no significant changes in steadystate $A \beta$ levels but nevertheless triggered increased thioflavin-positive plaque formation [31]. It is important to recognize that, although CatB is a lysosomal protease, it is also secreted into the extracellular space and is known to accumulate in amyloid deposits [31]. 
CatD, by contrast, is perhaps the best example of an $A \beta D P$ that exclusively regulates a single pool of $A \beta$. This is so because CatD is an aspartyl protease and therefore active only within the acidic environment present in lysosomes. CatD is the principal acidic ABDP in brain homogenates [48], and genetic deletion of CatD reduces $\mathrm{A} \beta$ degradation in soluble brain extracts by more than $95 \%$ at $\mathrm{pH} 4.5$ [33]. In the absence of APP over expression, genetic deletion of CatD results in a number of novel consequences. First, whereas diethylamine-extractable ('soluble') pools of endogenous $A \beta$ are relatively unchanged, CatD-null mice exhibit large increases in guanidinium-extractable ('insoluble') $\mathrm{A} \beta$ [33]. The absolute magnitude of the latter increases exceeds those obtained following deletion of IDE, NEP, or even both proteases simultaneously [33]. Deletion of CatD also results in highly consistent increases in the cerebral A $\beta 42 / 40$ ratio, an effect that is attributable to (aggregation-independent) differential degradation of $A \beta 42$ and $A \beta 40$ monomers [33]. CatD-null mice die prematurely [49], thus limiting the extent to which its role can be studied in animal models of AD. However, deletion of CatD in the Tg2576 line of APP transgenic mice leads to pronounced intracellular deposition of $A \beta$ by 3 weeks of age (MA Leissring, unpublished observations). Moreover, deletion of just one copy of CatD results in a significantly earlier onset of amyloid deposits in Tg2576 mice (MA Leissring, unpublished observations).

\section{Conclusions}

We have reviewed multiple lines of evidence that, collectively, strongly support the view that AD pathogenesis is differentially impacted by distinct pools of $A \beta$. Different pools of $A \beta$, in turn, are regulated to a substantial extent by proteolytic degradation. Given that a wide array of different A $\beta D P s$ exist, each with distinctive localization profiles, there is a compelling reason to believe that additional insights into the relative importance of different pools of $A \beta$ will be gained by continued study of specific A $\beta D P$.

Based on the strengths and weaknesses of the studies we have reviewed, several recommendations can be made to help future progress in this area become maximally impactful. First, although studies of individual proteases are helpful, significantly greater insight can be gained from the comparison of different proteases within the same animal model. In the absence of side-by-side comparisons, there will always be ambiguity as to whether observed effects are generalizable. Along these lines, there would appear to be particular value in investigating the consequences of targeting of the same protease to different subcellular compartments in vivo, as was done, for example, in cultured neurons with NEP [47].
A second recommendation is to extend the study of spatially distinct $A \beta D P s$ to animal models featuring aspects of $\mathrm{AD}$ pathology besides amyloid deposition. It seems likely that some pools of $A \beta$ might be differentially important for tau pathology, for instance. Therefore, it would be especially helpful to investigate the consequences of different AßDPs in animal models that develop both amyloid and tau pathology.

Our final recommendation is simply to encourage researchers to continue work in this important area. The proteases involved in $A \beta$ production have been intensively investigated for almost two decades, yet no effective therapeutic agents have emerged from these studies. By contrast, A $\beta$ DPs have not been investigated to anywhere near the same extent, even though they appear to be far more relevant to the more common, late-onset forms of AD. As we hope this review has made clear, there is abundant evidence that specific pools of $A \beta$ are, indeed, differentially involved in AD pathogenesis; different pools, in turn, are regulated to a large extent by different ABDPs. Future work in this area not only promises to provide further insight into the fundamental mechanisms of $\mathrm{AD}$ pathogenesis - an important enough goal to warrant further research - but also is anticipated to directly inform the relative probability of success of future therapies and, furthermore, to identify important factors (for example, protease inhibitors in clinical use) that may modulate risk for AD.

\section{Abbreviations \\ AD: Alzheimer's disease; ApoE: Apolipoprotein E; ApoJ: Apolipoprotein J; APP: Amyloid precursor protein; AB: Amyloid $\beta$-protein; ABDP: Amyloid $\beta$-protein-degrading protease; BACE1: Beta-site APP-cleaving enzyme-1; BRI: British familial dementia-associated protein; CatB: Cathepsin B; CatD: Cathepsin D; ER: Endoplasmic reticulum; IDE: Insulin-degrading enzyme; NEP: Neprilysin.}

\section{Competing interests}

The authors declare that they have no competing interests.

\section{Acknowledgments}

This work was supported by an Alzheimer's Disease Research Center Pilot Award (from NIH Grant P50 AG016574) to MAL.

\section{Note}

This article is part of a series on Abeta Catabolism, edited by Elizabeth Eckman. Other articles in this series can be found at http://alzres.com/series/ Abeta_catabolism

\section{Author details}

${ }^{1}$ Department of Neuroscience, Mayo Clinic, Birdsall Building, Room 117, Jacksonville, FL 32224, USA. ${ }^{2}$ School of Molecular \& Cellular Biology, Faculty of Biological Sciences, University of Leeds, Leeds LS2 9JT, UK.

Published: 13 August 2013

\section{References}

1. Selkoe DJ: The origins of Alzheimer disease: a is for amyloid. JAMA 2000, 283:1615-1617.

2. De Strooper B, Vassar R, Golde T: The secretases: enzymes with therapeutic potential in Alzheimer disease. Nat Rev Neurol 2010, 6:99-107. 
3. Vassar R: Beta-Secretase, APP and Abeta in Alzheimer's disease. Subcell Biochem 2005, 38:79-103.

4. Selkoe DJ: Translating cell biology into therapeutic advances in Alzheimer's disease. Nature 1999, 399:A23-A31.

5. Walsh DM, Selkoe DJ: Oligomers on the brain: the emerging role of soluble protein aggregates in neurodegeneration. Protein Pept Lett 2004, 11:213-228.

6. Citron M, Eckman CB, Diehl TS, Corcoran C, Ostaszewski BL, Xia W, Levesque G, St George Hyslop P, Younkin SG, Selkoe DJ: Additive effects of PS1 and APP mutations on secretion of the 42-residue amyloid beta-protein. Neurobiol Dis 1998, 5:107-116.

7. Vassar R, Citron M: Abeta-generating enzymes: recent advances in betaand gamma-secretase research. Neuron 2000, 27:419-422.

8. Saido T, Leissring MA: Proteolytic degradation of amyloid beta-protein. Cold Spring Harb Perspect Med 2012, 2:a006379.

9. Shinohara M, Petersen RC, Dickson DW, Bu G: Brain regional correlation of amyloid-beta with synapses and apolipoprotein $E$ in non-demented individuals: potential mechanisms underlying regional vulnerability to amyloid-beta accumulation. Acta Neuropathol 2013 125:535-547.

10. Belyaev ND, Kellett KA, Beckett C, Makova NZ, Revett TJ, Nalivaeva NN, Hooper NM, Turner AJ: The transcriptionally active amyloid precursor protein (APP) intracellular domain is preferentially produced from the 695 isoform of APP in a \{beta\}-secretase-dependent pathway. J Biol Chem 2010, 285:41443-41454.

11. Yamazaki T, Selkoe DJ, Koo EH: Trafficking of cell surface beta-amyloid precursor protein: retrograde and transcytotic transport in cultured neurons. J Cell Biol 1995, 129:431-442.

12. Haass C, Hung AY, Selkoe DJ: Processing of beta-amyloid precursor protein in microglia and astrocytes favors an internal localization over constitutive secretion. J Neurosci 1991, 11:3783-3793.

13. Busciglio J, Gabuzda DH, Matsudaira P, Yankner BA: Generation of betaamyloid in the secretory pathway in neuronal and nonneuronal cells. Proc Natl Acad Sci U S A 1993, 90:2092-2096.

14. Thinakaran $\mathrm{G}, \mathrm{Koo} \mathrm{EH}$ : Amyloid precursor protein trafficking, processing, and function. J Biol Chem 2008, 283:29615-29619.

15. Chyung JH, Raper DM, Selkoe DJ: Gamma-secretase exists on the plasma membrane as an intact complex that accepts substrates and effects intramembrane cleavage. J Biol Chem 2005, 280:4383-4392.

16. Gouras GK, Tsai J, Naslund J, Vincent B, Edgar M, Checler F, Greenfield JP, Haroutunian V, Buxbaum JD, Xu H, Greengard P, Relkin NR: Intraneuronal Abeta42 accumulation in human brain. Am J Pathol 2000, 156:15-20.

17. LaFerla FM, Green KN, Oddo S: Intracellular amyloid-beta in Alzheimer's disease. Nat Rev Neurosci 2007, 8:499-509.

18. Glabe C: Intracellular mechanisms of amyloid accumulation and pathogenesis in Alzheimer's disease. J Mol Neurosci 2001, 17:137-145.

19. Spuch C, Ortolano S, Navarro C: New insights in the amyloid-Beta interaction with mitochondria. J Aging Res 2012, 2012:324968.

20. Hansson CA, Frykman S, Farmery MR, Tjernberg LO, Nilsberth C, Pursglove SE, Ito A, Winblad B, Cowburn RF, Thyberg J, Ankarcrona M: Nicastrin, presenilin, $\mathrm{APH}-1$, and PEN-2 form active gamma-secretase complexes in mitochondria. J Biol Chem 2004, 279:51654-51660.

21. Pavlov PF, Wiehager B, Sakai J, Frykman S, Behbahani H, Winblad B, Ankarcrona M: Mitochondrial gamma-secretase participates in the metabolism of mitochondria-associated amyloid precursor protein. Faseb J 2011, 25:78-88.

22. Yang AJ, Chandswangbhuvana D, Margol L, Glabe CG: Loss of endosomal/ lysosomal membrane impermeability is an early event in amyloid Abeta1-42 pathogenesis. J Neurosci Res 1998, 52:691-698.

23. Schmitz A, Schneider A, Kummer MP, Herzog V: Endoplasmic reticulumlocalized amyloid beta-peptide is degraded in the cytosol by two distinct degradation pathways. Traffic 2004, 5:89-101.

24. Zhang Y, McLaughlin R, Goodyer C, LeBlanc A: Selective cytotoxicity of intracellular amyloid beta peptide1-42 through p53 and Bax in cultured primary human neurons. J Cell Biol 2002, 156:519-529.

25. Lee EK, Park YW, Shin DY, Mook-Jung I, Yoo YJ: Cytosolic amyloid-beta peptide 42 escaping from degradation induces cell death. Biochem Biophys Res Commun 2006, 344:471-477.

26. Zlokovic BV: Cerebrovascular transport of Alzheimer's amyloid beta and apolipoproteins J and E: possible anti-amyloidogenic role of the bloodbrain barrier. Life Sci 1996, 59:1483-1497.
27. Bu G: Apolipoprotein $\mathrm{E}$ and its receptors in Alzheimer's disease: pathways, pathogenesis and therapy. Nat Rev Neurosci 2009, 10:333-344

28. Belbin O, Carrasquillo MM, Crump M, Culley OJ, Hunter TA, Ma L, Bisceglio G, Zou F, Allen M, Dickson DW, Graff-Radford NR, Petersen RC, Morgan K, Younkin SG: Investigation of 15 of the top candidate genes for late-onset Alzheimer's disease. Hum Genet 2011, 129:273-282.

29. Leissring MA: Proteolytic degradation of the amyloid beta-protein: the forgotten side of Alzheimer's disease. Curr Alzheimer Res 2006, 3:431-435.

30. Nalivaeva NN, Beckett C, Belyaev ND, Turner AJ: Are amyloid-degrading enzymes viable therapeutic targets in Alzheimer's disease? J Neurochem 2012, 120:167-185.

31. Mueller-Steiner S, Zhou Y, Arai H, Roberson ED, Sun B, Chen J, Wang X, Yu G, Esposito L, Mucke L, Gan L: Antiamyloidogenic and neuroprotective functions of cathepsin B: implications for Alzheimer's disease. Neuron 2006, 51:703-714.

32. Zou K, Yamaguchi $H$, Akatsu H, Sakamoto T, Ko M, Mizoguchi K, Gong JS, Yu W, Yamamoto T, Kosaka K, Yanagisawa K, Michikawa M: Angiotensinconverting enzyme converts amyloid beta-protein 1-42 (Abeta(1-42)) to Abeta(1-40), and its inhibition enhances brain Abeta deposition. $J$ Neurosci 2007, 27:8628-8635.

33. Leissring MA, Reinstatler $L$, Sahara $T$, Roman $R$, Sevlever $D$, Saftig $P$, Levites $Y$, Golde TE, Burgess JD, Ertekin-Taner N, Eckman EA: Cathepsin D selectively degrades $A \beta 42$ and tau: implications for Alzheimer disease pathogenesis. In Society for Neuroscience. Chicago, IL: Society for Neuroscience; 2009. Program No. 139.108.

34. Moore BD, Chakrabarty P, Levites Y, Kukar TL, Baine AM, Moroni T, Ladd TB, Das P, Dickson DW, Golde TE: Overlapping profiles of Abeta peptides in the Alzheimer's disease and pathological aging brains. Alzheimers Res Ther 2012, 4:18

35. Walsh DM, Selkoe DJ: Deciphering the molecular basis of memory failure in Alzheimer's disease. Neuron 2004, 44:181-193.

36. Grundke-lqbal I, lqbal K, George L, Tung YC, Kim KS, Wisniewski HM: Amyloid protein and neurofibrillary tangles coexist in the same neuron in Alzheimer disease. Proc Natl Acad Sci U S A 1989, 86:2853-2857.

37. Gyure KA, Durham R, Stewart WF, Smialek JE, Troncoso JC: Intraneuronal abeta-amyloid precedes development of amyloid plaques in Down syndrome. Arch Pathol Lab Med 2001, 125:489-492

38. LaFerla FM, Tinkle BT, Bieberich CJ, Haudenschild CC, Jay G: The Alzheimer's A beta peptide induces neurodegeneration and apoptotic cell death in transgenic mice. Nat Genet 1995, 9:21-30.

39. McGowan E, Pickford F, Kim J, Onstead L, Eriksen J, Yu C, Skipper L, Murphy MP, Beard J, Das P, Jansen K, Delucia M, Lin WL, Dolios G, Wang R, Eckman CB, Dickson DW, Hutton M, Hardy J, Golde T: Abeta42 is essential for parenchymal and vascular amyloid deposition in mice. Neuron 2005, 47:191-199.

40. Lewis PA, Piper S, Baker M, Onstead L, Murphy MP, Hardy J, Wang R, McGowan E, Golde TE: Expression of BRI-amyloid beta peptide fusion proteins: a novel method for specific high-level expression of amyloid beta peptides. Biochim Biophys Acta 2001, 1537:58-62.

41. Sudoh S, Frosch MP, Wolf BA: Differential effects of proteases involved in intracellular degradation of amyloid beta-protein between detergentsoluble and -insoluble pools in CHO-695 cells. Biochemistry 2002, 41:1091-1099.

42. Hama E, Shirotani K, Iwata N, Saido TC: Effects of neprilysin chimeric proteins targeted to subcellular compartments on amyloid beta peptide clearance in primary neurons. J Biol Chem 2004, 279:30259-30264.

43. Whyteside AR, Turner AJ: Human neprilysin-2 (NEP2) and NEP display distinct subcellular localisations and substrate preferences. FEBS Lett 2008, 582:2382-2386.

44. Leissring MA, Farris W, Chang AY, Walsh DM, Wu X, Sun X, Frosch MP Selkoe DJ: Enhanced proteolysis of beta-amyloid in APP transgenic mice prevents plaque formation, secondary pathology, and premature death. Neuron 2003, 40:1087-1093.

45. Leissring MA: The $A B C$ s of $A \beta$-cleaving proteases. J Biol Chem 2008 283:29645-29649

46. Farris W, Schutz SG, Cirrito JR, Shankar GM, Sun X, George A, Leissring MA Walsh DM, Qiu WQ, Holtzman DM, Selkoe DJ: Loss of neprilysin function promotes amyloid plaque formation and causes cerebral amyloid angiopathy. Am J Pathol 2007, 171:241-251. 
47. Huang SM, Mouri A, Kokubo H, Nakajima R, Suemoto T, Higuchi M, Staufenbiel M, Noda Y, Yamaguchi H, Nabeshima T, Saido TC, Iwata N: Neprilysin-sensitive synapse-associated amyloid-beta peptide oligomers impair neuronal plasticity and cognitive function. J Biol Chem 2006, 281:17941-17951.

48. McDermott JR, Gibson AM: Degradation of Alzheimer's beta-amyloid protein by human cathepsin D. Neuroreport 1996, 7:2163-2166.

49. Saftig P, Hetman M, Schmahl W, Weber K, Heine L, Mossmann H, Koster A, Hess $B$, Evers $M$, von Figura $K$, Peters $C$ : Mice deficient for the lysosomal proteinase cathepsin $\mathrm{D}$ exhibit progressive atrophy of the intestinal mucosa and profound destruction of lymphoid cells. Embo J 1995, 14:3599-3608.

doi:10.1186/alzrt194

Cite this article as: Leissring and Turner: Regulation of distinct pools of amyloid $\beta$-protein by multiple cellular proteases. Alzheimer's Research \& Therapy 2013 5:37.

\section{Submit your next manuscript to BioMed Central and take full advantage of:}

- Convenient online submission

- Thorough peer review

- No space constraints or color figure charges

- Immediate publication on acceptance

- Inclusion in PubMed, CAS, Scopus and Google Scholar

- Research which is freely available for redistribution 